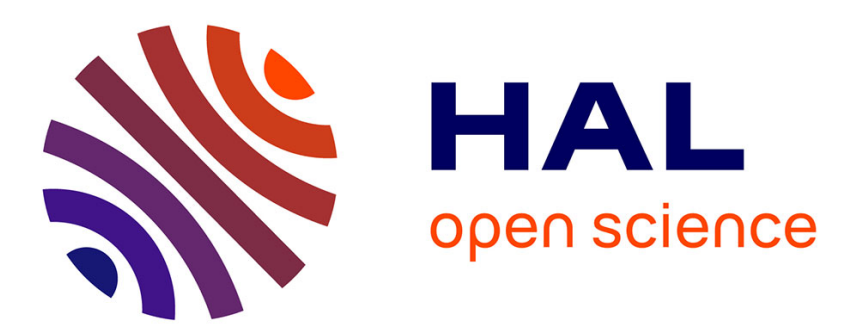

\title{
Reaction-Diffusion Finite Element Model of Lateral Line Primordium Migration to Explore Cell Leadership
}

Rachele Allena, Philip Maini

\section{To cite this version:}

Rachele Allena, Philip Maini. Reaction-Diffusion Finite Element Model of Lateral Line Primordium Migration to Explore Cell Leadership. Bulletin of Mathematical Biology, 2014, 76 (12), pp.3028-3050. 10.1007/s11538-014-0043-7 . hal-01096997

\section{HAL Id: hal-01096997 https://hal.science/hal-01096997}

Submitted on 18 Dec 2014

HAL is a multi-disciplinary open access archive for the deposit and dissemination of scientific research documents, whether they are published or not. The documents may come from teaching and research institutions in France or abroad, or from public or private research centers.
L'archive ouverte pluridisciplinaire HAL, est destinée au dépôt et à la diffusion de documents scientifiques de niveau recherche, publiés ou non, émanant des établissements d'enseignement et de recherche français ou étrangers, des laboratoires publics ou privés. 


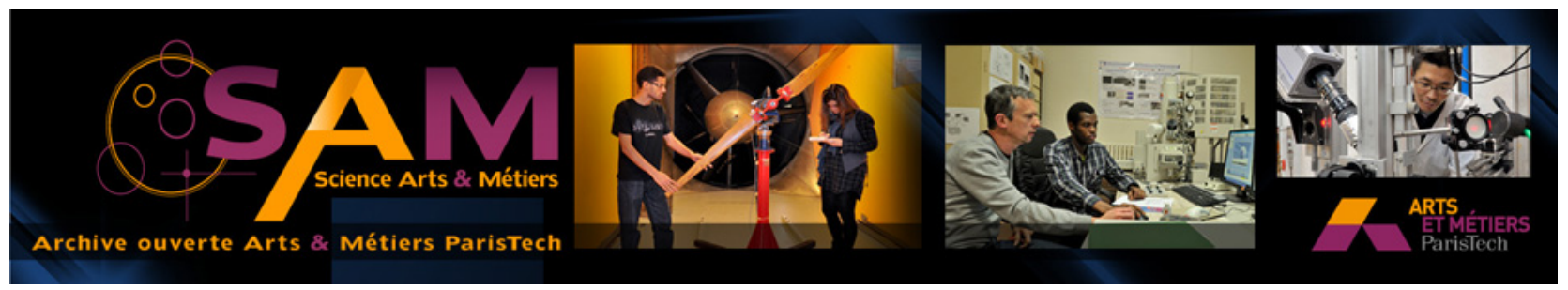

Science Arts \& Métiers (SAM)

is an open access repository that collects the work of Arts et Métiers ParisTech researchers and makes it freely available over the web where possible.

This is an author-deposited version published in: http://sam.ensam.eu

Handle ID: .http://hdl.handle.net/10985/9123

\section{To cite this version :}

Rachele ALLENA, Philip MAINI - Reaction-Diffusion Finite Element Model of Lateral Line Primordium Migration to Explore Cell Leadership - Bulletin of Mathematical Biology - Vol. 76, $n^{\circ} 12$, p.3028-3050 - 2014 


\title{
Reaction-Diffusion Finite Element Model of Lateral Line Primordium Migration to Explore Cell Leadership
}

\author{
R. Allena • P. K. Maini
}

\begin{abstract}
Collective cell migration plays a fundamental role in many biological phenomena such as immune response, embryogenesis and tumorigenesis. In the present work, we propose a reaction-diffusion finite element model of the lateral line primordium migration in zebrafish. The population is modelled as a continuum with embedded discrete motile cells, which are assumed to be viscoelastic and able to undergo large deformations. The Wnt/ß-catenin-FGF and $c x c r 4 b-c x c r 7 b$ signalling pathways inside the cohort regulating the migration are described through coupled reaction-diffusion equations. The coupling between mechanics and the molecular scenario occurs in two ways. Firstly, the intensity of the protrusion-contraction movement of the cells depends on the $c x c r 4 b$ concentration. Secondly, the intra-synchronization between the active deformations and the adhesion forces inside each cell is triggered by the $c x c r 4 b-c x c r 7 b$ polarity. This influences the inter-synchronization between the cells and results in two main modes of migration: uncoordinated and coordinated. The main objectives of the work were (i) to validate our assumptions with respect to the experimental observations and (ii) to decipher the mechanical conditions leading to efficient migration of the primordium. To achieve the second goal, we will specifically focus on the role of the leader cells and their position inside the population.
\end{abstract}

\footnotetext{
R. Allena $(\varangle)$

Arts et Metiers ParisTech, LBM, 151 Bd de l'hôpital, 75013 Paris, France

e-mail: rachele.allena@ensam.eu

P. K. Maini

Wolfson Centre for Mathematical Biology, Mathematical Institute, University of Oxford, Andrew Wiles Building, Woodstock Road, Oxford OX2 6GG, UK
} 
Keywords Collective migration - Continuum mechanics $\cdot$ Reaction-diffusion equation · Cell leadership

\section{Introduction}

Cell migration is essential for many processes in biology. In the case of single cell migration, for example, neural crest cells and immune system cells, one may observe synchronization between the protrusion-contraction movement of the cell body and the adhesion forces between the cell and the extracellular matrix (ECM), which is necessary for efficient movement (Allena and Aubry 2012). In the case of collective cell migration (e.g. gastrulation, epithelial wound healing), cells move as populations by adhering to each other via cell-cell junctions (Friedl and Gilmour 2009; Rørth 2007). While in vitro studies have led to a better understanding of the mechanisms regulating single cell migration, several fundamental aspects of collective cell migration in sheets are still ambiguous and poorly explored. Unresolved questions include, for instance, whether all the cells actively participate in the migration process or whether only the leader cells sense an external cue and, through other chemical or mechanical signals, instruct the followers (Aman and Piotrowski 2008; López-Schier 2010). Additionally, it is unclear how such a polarity between the front and the rear edges of the population is maintained and how the biomechanical signals are possibly transmitted from the leader cells to the follower cells to guarantee both the synchronization and the efficiency of the migration.

Deciphering the mechanisms controlling collective cell migration not only advances our knowledge of basic, fundamental biology, but may also be clinically relevant in cases where cell movement occurs in response to injury, or in disease, such as cancer (Friedl and Gilmour 2009; Ilina and Friedl 2009). For this purpose, the zebrafish lateral line primordium (LLP) constitutes a powerful biological model, and it has been experimentally investigated due to its simplicity and accessibility (Aman and Piotrowski 2009, 2011).

\subsection{LLP Migration}

The LLP is a population formed by over 100 epithelial cells that arises posterior to the ear and starts to migrate from the head to the tail of the animal along the embryonic trunk at about $20 \mathrm{~h}$ post-egg fertilization (hpf). The LLP completes its migration at around $42 \mathrm{hpf}$, after having travelled approximately 3,000 $\mathrm{mm}$ (Gompel et al. 2001). During the migration, the trailing two-thirds of the cohort arrange themselves into rosettes (i.e. clusters of 20 cells) that are periodically deposited and eventually differentiate as the functional organs of the lateral line, called neuromasts (Aman and Piotrowski 2009; Anand et al. 2007).

The molecular regulation of LLP migration has been investigated in detail over recent years. Normal migration (i.e. along the embryo trunk) seems to be ensured by the polarized expression of both $c x c r 4 b$ and $c x c r 7 b$, two chemokine receptors of the ligand cxcl12a (Dambly-Chaudière et al. 2007; Valentin et al. 2007), which is expressed by the cells along the migration path (David et al. 2002). In fact, $c x c r 4 b$ is mostly expressed 

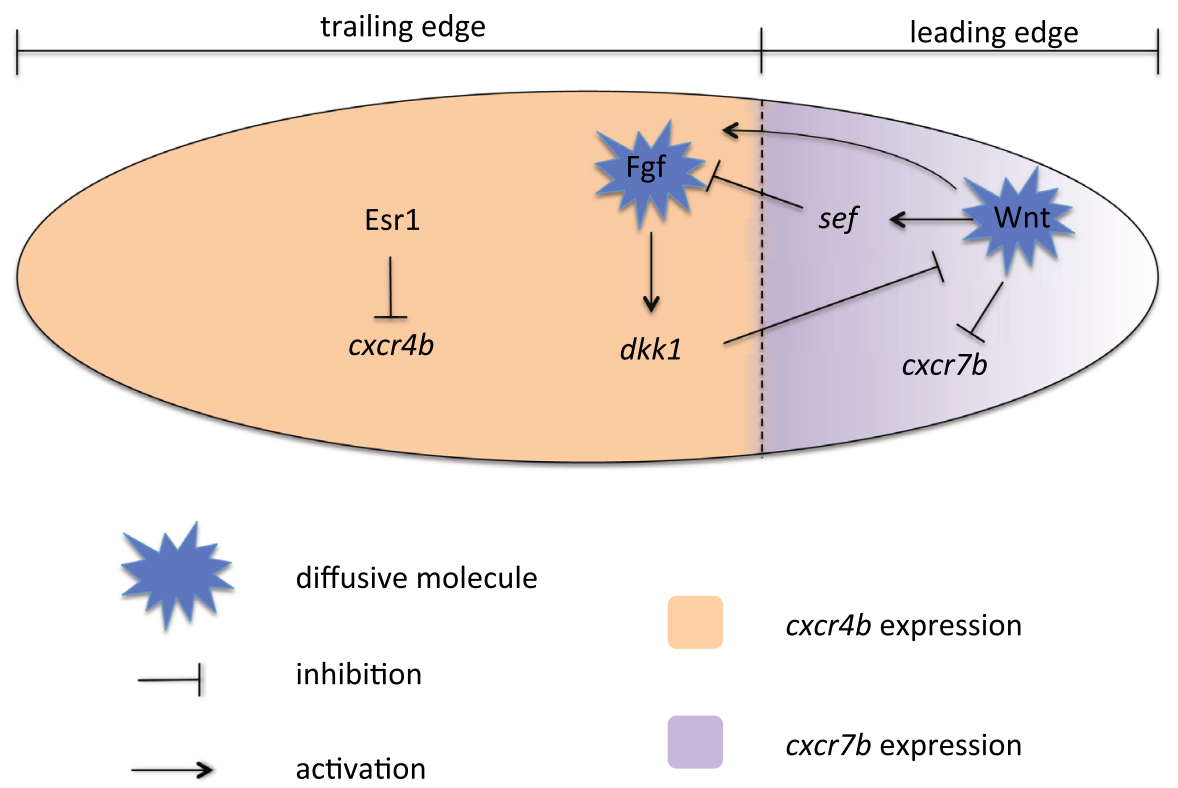

Fig. 1 Simplified LLP geometry and signalling network over the population. Wnt/ß-catenin and FGF (which are considered here as diffusive molecules) signalling is activated at the leading and trailing edge of the LLP, respectively. Such a polarity is controlled by the expression of the signalling inhibitors $d k k 1$ and sef, respectively. Simultaneously, Wnt/ß-catenin inhibits the expression of $c x c r 7 b$ in the leading cells, while the oestrogen receptor Esr1 ensures the inhibition of cxcr $4 b$ expression in the trailing cells (see Sect. 1.1 for further details) (Color figure online)

in the leading cells of the LLP, while $c x c r 7 b$ is mostly found in the trailing cells. Additionally, it has been observed that, in the absence of chemokine signalling, the cells within the LLP still migrate, but they lose their coordinated directionality (Haas and Gilmour 2006).

Aman and Piotrowski (2008) inferred that such a polarity may be controlled by a complex cell signalling network, which is based on feedback interactions between the Wnt/B-catenin ${ }^{1}$ and $\mathrm{FGF}^{2}$ pathways that circumscribe the activation of the two chemokines to the opposite poles of the LLP (Aman and Piotrowski 2008).

This complex signalling network is represented in Fig. 1. Wnt/B-catenin signalling is activated only in the first several rows of leader cells, where it triggers the expression of FGF3 and FGF10 ligands. Concurrently, the Wnt/ß-catenin pathway upregulates the FGF signalling inhibitor sef in the leading cells. Thus, FGF pathway activation is inhibited in the leading cells (even though these cells express FGF ligands), and FGF target genes are induced only in the trailing cells. In turn, FGF signalling in the back of the LLP activates the Wnt/B-catenin inhibitor $d k k l$, which then results in the restriction of the Wnt/ß-catenin pathway to the leading cells. Finally, Wnt/ß-catenin

\footnotetext{
$1 \mathrm{Wnt} / \mathrm{B}$-catenin is the canonical Wnt pathway.

2 FGF stands for fibroblast growth factor.
} 
activation constrains the $c x c r 7 b$ expression in the leading cells of the LLP, whereas $c x c r 4 b$, which is homogeneously distributed within the LLP at the onset of migration (Dambly-Chaudière et al. 2007; Gamba et al. 2010), is inhibited in the trailing cells via the oestrogen receptor Esr1, which is directly produced by Wnt (Gamba et al. 2010). This Wnt/ß-catenin-FGF feedback mechanism not only ensures the polarized expression of the two chemokine receptors, it also affects the morphogenesis of the LLP. The Wnt/ß-catenin activation restricts the FGF-dependent neurogenesis to the trailing edge resulting in an unpatterned (i.e. no rosette generation) leading edge. According to the analysis of FGF-depleted LLP which concurrently loses rosettes and stops migrating, it was deduced that rosette formation was required for migration (Lecaudey et al. 2008; Nechiporuk and Raible 2008). However, Aman and Piotrowski (Aman and Piotrowski 2008) later observed that in the absence of Wnt/ß-catenin and FGF signalling the LLP migrates normally even in the absence of rosette deposition and that the stalling in FGF-depleted LLP is due to ectopic Wnt/ß-catenin signalling and the consequent inhibition of $c x c r 7 b$. Therefore, the Wnt/B-catenin and FGF pathways must be strongly coupled to guarantee forward migration as well as the periodic deposition of the rosettes. Nevertheless, it is still unclear whether all the cells actively participate in the migration process or only the leader cells sense the signal and, through other chemical or mechanical signals, instruct the followers (Aman and Piotrowski 2008). In fact, the normal migration of the LLP appears to follow a linear gradient of the chemokine stromal-derived factor 1 (SDF-1) which depends on the expression of $c x c r 4 b$ in the leading cells (Haas and Gilmour 2006). Some experiments have shown that only a few $c x c r 4 b$ expressed cells at the leading edge of the LLP are required to guide the movement of the population. Therefore, it has been proposed that $c x c r 4 b$ expressing cells at the leading edge may be responsible for sensing the SDF-1 gradient, while $c x c r 7 b$ mainly shapes the gradient across the LLP. Nonetheless, further measurements of the SDF-1 gradient throughout the population are needed to confirm such a hypothesis and the mechanism by which the cells follow the gradient is still unclear (Rørth 2007).

\subsection{Objectives of the Present Work}

Several models on collective cell migration can be found in the literature using either agent-based (Graner and Glazier 1992; Vedel et al. 2013; Yamao et al. 2011) or continuum approaches (Arciero et al. 2011; Sherratt and Murray 1990, 1991). Recently, Streichan et al. (2011) and Di Costanzo et al. (2014) have proposed two two-dimensional (2D) models specifically focusing on the collective migration of the LLP. The former is a discrete model in which a cell is represented as a polygon in a lattice and the tissue consists of a collection of cells. The population moves within a constant ligand distribution along a line, and as cells migrate, the frontal edge of the LLP becomes shifted to higher concentrations, while the rear edge is displaced from higher concentrations. Such an asymmetry allows the LLP to maintain a preferred direction of migration over long distances, while growing in size to deposit rosettes during migration. The latter proposes a hybrid description of the biological system, which considers both the cellular and the molecular scales. A discrete approach is used to represent the cellular 
level, which includes the equation of motion and the equation of state leader-follower for each cell. A continuum approach is employed to define the molecular level and is based on the equations for the chemical signal involved. Under suitable conditions, the model is able to trigger the formation of rosettes, whose stability has been numerically evaluated and compared with experimental observations.

Contrary to these previous models (Di Costanzo et al. 2014; Streichan et al. 2011), here we propose a 2D finite element model of the LLP which only focuses on the LLP migration and does not take into account the growth of the population and rosette formation. Nonetheless, the model constitutes a significant extension of the previous one proposed by the first author in Allena et al. (2013) since it couples mechanics with molecular signalling in order to provide an exhaustive representation of the biological system.

The model is based on the following assumptions:

- as in Di Costanzo et al. (2014), a hybrid description is employed. In fact, the cell population is modelled as a continuum with embedded discrete motile cells which are assumed to be viscoelastic and able to undergo large deformations (Allena et al. 2013), while molecules are considered as continuous concentrations;

- in contrast to previous models (Di Costanzo et al. 2014; Streichan et al. 2011) where the molecular scenario inside the LLP only includes a limited number of molecules and interactions, here both the Wnt/ß-catenin-FGF and the $c x c r 4 b-$ $c x c r 7 b$ signalling pathways with the associated receptors and inhibitors are taken into account. Their spatiotemporal evolution is characterized by coupled reactiondiffusion equations;

- as in the previous works of the first author (Allena 2013; Allena and Aubry 2012; Allena et al. 2013), the decomposition of the deformation gradient is used to take into account both the active (i.e. protrusion and contraction) and the elastic (i.e. generated by the interactions with the ECM) deformations of the cells;

- mechanics is coupled in two ways with the molecular framework, which constitutes the main novelty of the present work. First, the intensity of the protrusioncontraction movement of the cells depends on the $c x c r 4 b$ concentration, while the intra-synchronization (Allena et al. 2013) inside each cell (i.e. the synchronization between the protrusion-contraction movement of the cell and the adhesion forces exerted by the cell to move forward) is triggered by the $c x c r 4 b-c x c r 7 b$ polarity. This influences the inter-synchronization (Allena et al. 2013) between the cells (i.e. the coordination between the cells) and results in two main modes of migration: uncoordinated and coordinated, which correspond, respectively, to the absence or the presence of $c x c r 4 b-c x c r 7 b$ polarity.

For the present work, we have two main objectives: first, we want to validate, with respect to the experimental observations in the literature, our modelling assumptions on the molecular pathway interactions and its coupling with the mechanics of the LLP. In order to do so, we will consider four different mutants as described in Aman and Piotrowski (2008), and we will analyse the results in terms of migration mode, efficiency and stress distribution and compare them to the experimental observations. Second, we will try to unravel the required mechanical conditions for efficient migra- 
tion of the LLP. To achieve such a goal, we will focus particularly on the role of the leader cells and their position within the population.

\section{The Model}

\subsection{Geometry of the LLP}

We model the LLP as a continuum with a free boundary approximated by an ellipse with semi-axes $L$ and $l$ at the onset of migration (i.e. 20hpf) (Fig. 2a). The ellipse includes the cell network $\Omega_{n}$, which is described via a characteristic function $h_{n}(\boldsymbol{p})$ (Appendix Sect. "LLP Geometry", Eq. 8) and is constituted by 106 cells, which are in contact with each other and embedded in the extracellular matrix (ECM) $\Omega_{\mathrm{ECM}}$ (Fig. 2b), which is also defined by a characteristic function $h_{\mathrm{ECM}}(\boldsymbol{p})$ (Appendix Sect.
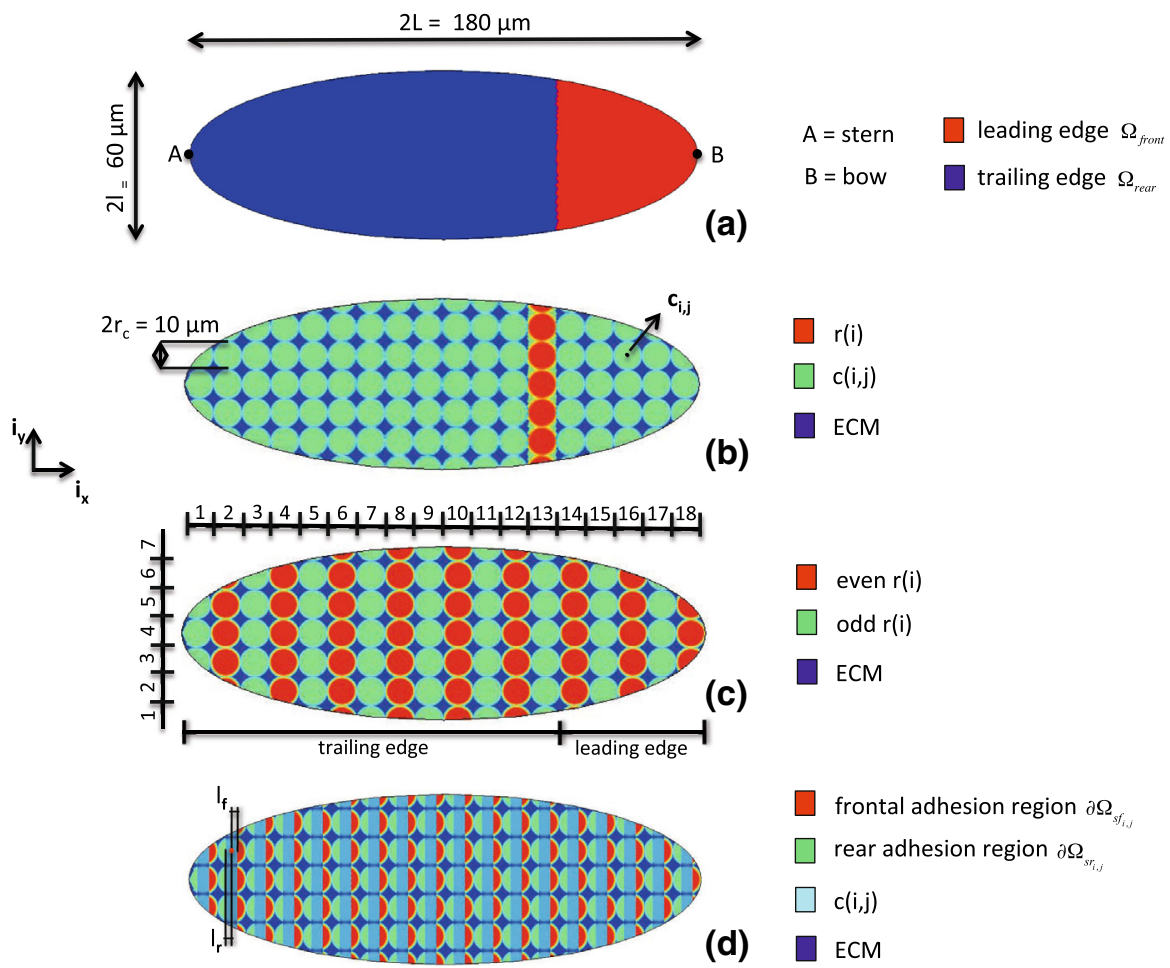

Fig. 2 a Simplified geometry of the LLP with the leading (red) and trailing (blue) edges. b Representation of the cell network $h_{n}(\boldsymbol{p})$. Each cell $c(i, j)$ (green) has a circular shape with radius $r_{\mathrm{c}}$ and centre $\boldsymbol{c}_{i, j}$. c The elliptical shape of the LLP is divided into cell rows, $r(i)$, which are numbered from the "stern" to the "bow" of the ellipse (even rows in red, odd rows in green). The first 5 rows constitute the leading edge, while the remaining 13 rows constitute the trailing edge. The ECM (blue) fills the interstices between the cells. $\mathbf{d}$ Representation of the initial frontal $\left(\partial \Omega_{\mathrm{sf}_{i, j}}\right.$, red $)$ and rear $\left(\partial \Omega_{\mathrm{sr}_{i, j}}\right.$, green $)$ adhesion surfaces which are defined by the distances of the cell centre $c_{i, j}$ from the frontal $\left(l_{\mathrm{f}}\right)$ and rear $\left(l_{\mathrm{r}}\right)$ region (Color figure online) 
"LLP Geometry", Eq. 9). At the initial time step, each cell $c(i, j)$ inside the population has a circular shape (Fig. 2b, Appendix Sect. "LLP Geometry", Eq. 11) with radius $r_{c}$ and centre $c_{i, j}\left(c_{i, j_{x}}, c_{i, j_{y}}\right)$, where the indices $i$ and $j$ indicate the position of the cell, respectively, along the major and minor axes of the ellipse (Fig. 2c, Appendix Sect. "LLP Geometry", Eq. 10). Each cell is equipped with frontal $\left(\partial \Omega_{\mathrm{sf}_{i, j}}\right)$ and rear $\left(\partial \Omega_{\mathrm{sr}_{i, j}}\right)$ regions (Fig. $\left.2 \mathrm{~d}\right)$, which are defined through two characteristic functions $h_{\mathrm{sf}_{i, j}}$ and $h_{\mathrm{sr}_{i, j}}$ (Appendix Sect. "LLP Geometry", Eq. 12) and depend on the distances $l_{\mathrm{f}}$ and $l_{\mathrm{r}}$ between the cell centre $c_{i, j}$ the corresponding regions (Fig. 2d, Appendix Sect. "LLP Geometry", Eq. 12). These regions allow the cell to adhere to the ECM. Finally, we assume here that the cells migrate along the horizontal axis $i_{x}$.

\subsection{Molecular Framework}

As described in Sect. 1.1, LLP migration is controlled by a very complex interaction network of molecules and chemokines. Although a few processes and interactions remain unclear, we propose a set of four coupled reaction-diffusion equations derived from the experimental observations proposed in Aman and Piotrowski (2008, 2009, 2011) and based on the following assumptions:

(i) we consider two molecules (Wnt-ß-catenin and FGF) and two chemokines (cxcr $4 b$ and $c x c r 7 b$ );

(ii) start of polarisation of Wnt/B-catenin and $c x c r 4 b-c x c r 7 b$ are assume to occur between the leading $\left(\Omega_{\text {front }}\right)$ and the trailing $\left(\Omega_{\text {rear }}\right)$ cells (Fig. $\left.2 a\right)$ of the LLP, which are described through two characteristic functions $h_{\text {front }}$ and $h_{\text {rear }}$, respectively (Appendix Sect. "Leading and Trailing Edge of the LLP", Eq. 14). The former includes 5 cell rows, while the latter is constituted by the remaining 13 rows;

(iii) only Wnt/ß-catenin signalling activation is considered, and it occurs in the leading edge $\Omega_{\text {front }}$ of the LLP;

(iv) $\mathrm{Wnt} / \mathrm{\beta}$-catenin produces FGF and in the frontal edge $\Omega_{\text {front }}$ of the LLP simultaneously inhibits it through sef;

(v) only Wnt/ß-catenin and FGF are considered as diffusive molecules;

(vi) $c x c r 4 b$ and $c x c r 7 b$ are homogeneously distributed throughout the LLP at the onset of migration (i.e. $c x c r 4 b=c x c r 7 b=1$ at $20 \mathrm{hpf}$ );

(vii) $F G F, c x c r 4 b$ and $c x c r 7 b$ autoproduce themselves;

(viii) the inhibition of $c x c r 4 b$ in the trailing cells $\Omega_{\text {rear }}$ is directly controlled by FGF.

Therefore, the model equations take the form:

$$
\begin{aligned}
& \frac{\partial[W]}{\partial t}=\underbrace{D_{\mathrm{a}} \nabla^{2}[W]}_{\text {diffusion }}+\underbrace{S_{\mathrm{a}}[W](1-[W]) h_{\text {front }}}_{\text {signalling }}-\underbrace{R_{\mathrm{a}}[W][F] h_{\text {rear }}}_{\text {reaction by } d k k 1} \\
& \frac{\partial[F]}{\partial t}=\underbrace{D_{\mathrm{b}} \nabla^{2}[F]}_{\text {diffusion }}+\underbrace{P_{\mathrm{b}}[W](1-[F])}_{\text {production }}-\underbrace{R_{\mathrm{b}}[F][W] h_{\text {front }}}_{\text {reaction by sef }}
\end{aligned}
$$




$$
\begin{gathered}
\frac{\partial\left[c_{4}\right]}{\partial t}=\underbrace{P_{\mathrm{c}}\left[c_{4}\right]\left(1-\left[c_{4}\right]\right)}_{\text {production }}-\underbrace{R_{\mathrm{c}}\left[c_{4}\right][F]}_{\text {reaction by } F g f} \\
\frac{\partial\left[c_{7}\right]}{\partial t}=\underbrace{P_{\mathrm{d}}\left[c_{7}\right]\left(1-\left[c_{7}\right]\right)}_{\text {production }}-\underbrace{R_{\mathrm{d}}\left[c_{7}\right][W]}_{\text {reaction by } W n t}
\end{gathered}
$$

where $[W]=\mathrm{Wnt} / B$-catenin, $[F]=F G F,\left[c_{4}\right]=\operatorname{cxcr} 4 b,\left[c_{7}\right]=\operatorname{cxcr} 7 b$ indicate the dimensionless and normalized concentrations. $D_{i}, P_{i}, R_{i}$ and $S_{i}$ are the diffusion coefficients, production, reaction and signalling rates, respectively, for each molecule. Finally, Neumann boundary conditions have been applied on the continuum domain of the LLP for all the variables.

\subsection{Mechanics of the Model}

The cells are assumed to consist of two phases: (i) a solid-like phase (the actin filaments) where the cyclic active deformations (i.e. protrusion and contraction) take place and (ii) a fluid-like phase, which includes some particles (the organelles, fluid elastic) embedded in a fluid (cytoplasm, fluid viscous). As in previous work of the first author (Allena and Aubry 2012; Allena et al. 2013), a 2D generalized Maxwell model has been used to reproduce such a behaviour (Appendix Sect. "Constitutive Model"). Since the cells within the cohort may undergo large rotations and deformations during their locomotion, a fully nonlinear tensorial approach is required. The ECM is assumed to be a viscoelastic material.

Newton's law, applied to the continuum with respect to the initial configuration $X$, yields

$$
\rho_{\mathrm{cells}} a=\operatorname{Div}_{X}\left(J \sigma F^{-T}\right)+f_{a d h}
$$

where $\rho_{\text {cells }}$ is the cell density, $a$ the acceleration, $\sigma$ the Cauchy stress, $F$ the deformation gradient, $J$ its determinant, $\boldsymbol{D} \boldsymbol{i} \boldsymbol{v}_{\boldsymbol{X}}$ the divergence with respect to the initial position and $F^{-T}$ the inverse transpose of the matrix $F$ (Holzapfel 2000; Taber 2004). The term $f_{\text {adh }}$ defines the viscous adhesion forces between the cell and the substrate and may be decomposed into a frontal $\left(f_{\mathrm{f}}\right)$ and a rear $\left(f_{\mathrm{r}}\right)$ force as follows:

$$
\begin{gathered}
\boldsymbol{f}_{f}(\boldsymbol{n})=-\mu_{\mathrm{f}} h_{\mathrm{e}}\left(-\frac{\partial \boldsymbol{F}_{\mathrm{sa}}}{\partial t}\right) h_{\mathrm{sf}_{i, j}}(\boldsymbol{u}) \frac{\partial \boldsymbol{u}}{\partial t} \\
\boldsymbol{f}_{\mathrm{r}}(\boldsymbol{n})=-\mu_{\mathrm{r}} h_{\mathrm{e}}\left(\frac{\partial \boldsymbol{F}_{\mathrm{sa}}}{\partial t}\right) h_{\mathrm{sr}_{i, j}}(\boldsymbol{u}) \frac{\partial \boldsymbol{u}}{\partial t}
\end{gathered}
$$

where $\mathbf{n}$ is the normal vector to the boundary of the cell $c(i, j), \mu_{\mathrm{f}}$ and $\mu_{\mathrm{r}}$ are the friction force viscosities and $\boldsymbol{u}$ is the displacement of the cell $c(i, j)$ with respect to the ECM. The characteristic function $h_{\mathrm{e}}$ is the key ingredient since it links the adhesion forces exerted by the cell $c(i, j)$ on the ECM with the cyclic protrusion-contraction movement of the cell, which is expressed by $\boldsymbol{F}_{\text {sa }}$ (Allena 2013; Allena and Aubry 2012) and will be defined in the next section. 


\subsection{Coordinated and Uncoordinated Regime of Cells}

According to the literature (Dambly-Chaudière et al. 2007; Valentin et al. 2007), normal migration (i.e. coordinated movement of the cells along the trunk of the zebrafish) is determined by the polarized expression of the two chemokines $c x c r 4 b$ and $c x c r 7 b$. If such a spatial pattern is not achieved, the cells either stall or migrate in an uncoordinated way. Thus, for the present model, we distinguish between two main modes of migration and of inter-synchronization (Allena et al. 2013):

(i) uncoordinated migration: all the cells are active (i.e. they develop a specific intersynchronization (Allena et al. 2013)), but they migrate at their own pace (i.e. they are not necessarily synchronized with their neighbours);

(ii) coordinated migration: once the $c x c r 4 b-c x c r 7 b$ polarization is achieved, a wave progressively covers the LLP, which activates, one by one, the rows of cells beginning at the leading row and travelling back towards the trailing edge (Haas and Gilmour 2006; Nechiporuk and Raible 2008) and the cells start migrating in a synchronized manner.

Then, the cyclic protrusion-contraction movement, which is assumed to occur in the solid phase of each cell, is expressed as a uniaxial deformation through the solid active deformation tensor $\boldsymbol{F}_{\text {sa }}$ as follows

$$
\boldsymbol{F}_{\mathrm{sa}}=\underbrace{e_{\mathrm{a}, \mathrm{uc}} h_{\mathrm{uc}} \boldsymbol{i}_{x} \otimes \boldsymbol{i}_{x}}_{\text {uncoordinated migration }}+\underbrace{e_{\mathrm{a}, \mathrm{c}} h_{\mathrm{c}} \boldsymbol{i}_{x} \otimes \boldsymbol{i}_{x}}_{\text {coordinated migration }}
$$

where $e_{\mathrm{a}, \mathrm{c}}$ and $e_{\mathrm{a}, \mathrm{uc}}$ describe the cyclic deformation of protrusion-contraction (Eq. 31) and $\otimes$ indicates the tensorial product. $h_{\mathrm{c}}$ and $h_{\mathrm{uc}}$ are two characteristic functions which define the specific conditions on the $c x c r 4 b$ and $c x c r 7 b$ concentrations determining the switch between the uncoordinated and the coordinated migration (Appendix Sect. "Coordinated and Uncoordinated Migration", Eq. 30).

It should be remarked that the coupling between the molecular and the mechanical frameworks of the system is here twofold since (i) the transition between the uncoordinated and the coordinated migration depends on the polarization of the two chemokines $c x c r 4 b$ and $c x c r 7 b$ and (ii) the intensity of the protrusion-contraction movement during both the coordinated and uncoordinated migration of the cells depends on the concentration of the $c x c r 4 b$ chemokine.

\section{Results}

The numerical simulations have been run using COMSOL Multiphysics $3.5 \mathrm{a}^{\circledR}$ and are shown at time intervals of 1 day. The cell population has an initial geometry with semi-axes $L$ and $l$ equal to 90 and $30 \mu \mathrm{m}$, respectively (Fig. 2a). The cell network represented by $h_{\mathrm{n}}(\boldsymbol{p})$ includes 18 cell rows $\left(N_{\mathrm{c}}=i_{\max }=18\right.$, Appendix Sect. "LLP Geometry"), and each cell $c(i, j)$ has a radius $r_{\mathrm{c}}=5 \mu \mathrm{m}$ (Allena 2013; Allena and Aubry 2012). The distances of $\boldsymbol{c}_{i, j}$ from the frontal $\left(l_{\mathrm{f}}\right)$ and rear $\left(l_{\mathrm{r}}\right)$ adhesion surfaces have both been fixed to $2 \mu \mathrm{m}$ (Allena 2013; Allena and Aubry 2012), which leads to 
an area of $25 \mu \mathrm{m}^{2}$ covered by the adhesion surfaces $\partial \Omega_{\mathrm{sf}_{i, j}}$ and $\partial \Omega_{\mathrm{sr}_{i, j}}$ (Fig. $2 \mathrm{~d}$ ), and the viscous coefficients $\mu_{\mathrm{f}}$ and $\mu_{\mathrm{r}}$ have been set to $10^{8} \mathrm{~Pa} / \mathrm{m}$ (Allena 2013; Allena and Aubry 2012). The Young's moduli of the solid elastic $\left(E_{\mathrm{se}}\right)$ and the fluid elastic $\left(E_{\mathrm{fe}}\right)$ phases of the cells have been chosen equal to $10^{4} \mathrm{~Pa}$ (Allena 2013; Allena and Aubry 2012; Laurent et al. 2005) and 100 Pa (Allena 2013; Allena and Aubry 2012), respectively. The Poisson ratios of the solid elastic $\left(v_{\mathrm{se}}\right)$ and the fluid elastic $\left(v_{\mathrm{fe}}\right)$ phases have been set to 0.3 and 0.4 , respectively, while the viscosity $\mu_{\mathrm{fv}}$ of the fluid viscous phase has been set to $3 \times 10^{5} \mathrm{Pas}$ (Bausch et al. 1999; Drury and Dembo 2001). The viscosity of the ECM has been fixed to $3 \times 10^{5} \mathrm{~Pa}$ (Bausch et al. 1999; Drury and Dembo 2001), and the density $\rho_{\text {cells }}$ of the cells is equal to $1,000 \mathrm{~kg} / \mathrm{m}^{3}$ (Fukui et al. 2000). The main geometrical, mechanical and material parameters of the model are listed in Table 1.

\subsection{The Model Correctly Reproduces Specific Mutant Behaviour}

For the first set of simulations, only the reaction-diffusion equations have been implemented in order to illustrate the ability of the model to reproduce molecule-chemokine patterns. Specifically, we have compared our numerical results to the experimental ones observed by Aman and Piotrowski (2008) who have analysed the wild-type $(w t)$ embryo and three mutants: the adenomatous polypolis coli $(a p c)^{3}$ embryo, the $S U 5402^{4}$ embryo and the $d k k l^{5}$ embryo. We describe in detail the main pattern characteristics of each one of these mutants as they have been experimentally observed (Aman and Piotrowski 2008) (Fig. 3):

- the wt embryo displays definite spatial polarizations for Wnt/B-catenin and FGF as well as for $c x c r 4 b$ and $c x c r 7 b$;

- the apc embryo presents a uniform distribution of both Wnt/B-catenin and FGF signalling;

- the SU5402 embryo is very similar to the apc embryo. In fact, SU5402 inhibits FGF signalling, whereas Wnt/B-catenin is still active throughout the whole LLP;

- finally, for the $d k k 1$ embryo, both Wnt/ß-catenin and FGF signalling are not activated. Nevertheless, $c x c r 7 b$ and the $c x c r 7 b$ are still present in the leading and trailing cells, respectively.

To numerically obtain the same patterns, we have first set the diffusive, signalling, production and reaction coefficients for each molecule and chemokine as they appear in Eqs. (1-4) for the wt embryo (see Table 2). Second, according to the previous remarks, Eqs. (1-4) have been changed and the coefficients tuned for each mutant (see Table 2 and Appendix Sect. "Description of Mutants"). In Fig. 4 (columns from 2 to 5 ), the normalized concentrations of the molecules and chemokines at the end of the simulations are shown for each mutant. A normalized concentration equal to 1 (red)

\footnotetext{
3 apc is a protein regulating $\mathrm{Wnt} / \mathrm{B}$-catenin signalling and ensuring association with the microtubules, which is necessary for normal migration, via the $\mathrm{C}$ terminus.

4 SU5402 is a fibroblast growth factor receptor (FGFR)-specific tyrosine kinase inhibitor.

$5 d k k 1$ is a diffusible inhibitor of the $\mathrm{Wnt} / ß$-catenin pathway.
} 


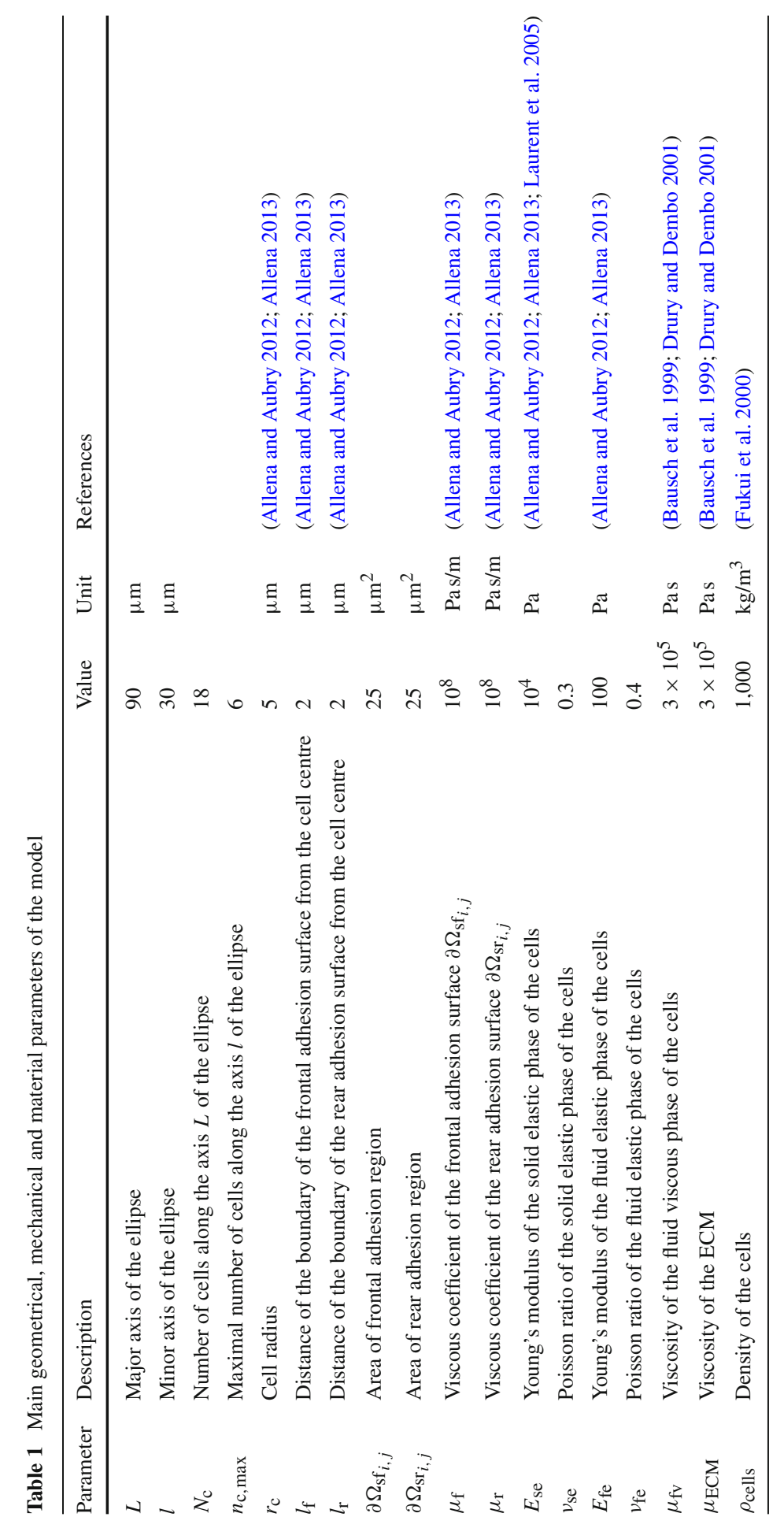




\begin{tabular}{|c|c|c|c|c|c|}
\hline Embryo & $\begin{array}{l}\text { Wnt/B-catenin } \\
\text { expression }\end{array}$ & $\begin{array}{c}\text { FGF } \\
\text { expression }\end{array}$ & $\begin{array}{c}c x c r 4 b \\
\text { expression }\end{array}$ & $\begin{array}{c}c x c r 7 b \\
\text { expression }\end{array}$ & Migration \\
\hline$w t$ & & & & & +++ \\
\hline$a p c$ & & & & & --- \\
\hline SU5402 & & & & & --- \\
\hline$d k k 1$ & & & & & +++ \\
\hline
\end{tabular}

Fig. 3 Summary of molecule and chemokine patterns and the associated migration behaviour for the four mutants tested in Aman and Piotrowski (2008) (Sect. 3.1) ('+++' and '- - -' indicate normal and abnormal migration, respectively; colored region in the LLP = molecule or chemokine expression; white region in the LLP $=$ no expression of the molecule or chemokine) (Color figure online)

Table 2 Reaction-diffusion coefficients of the model

\begin{tabular}{lllllll}
\hline Parameter & Description & \multicolumn{3}{l}{ Value } & & \multirow{2}{*}{ Unit } \\
\cline { 3 - 5 } & & $w t$ & $a p c$ & $S U 5042$ & $d k k 1$ & \\
\hline$D_{\mathrm{a}}$ & Diffusive coefficient for Wnt/B-catenin & $1 \mathrm{e}-11$ & $1 \mathrm{e}-11$ & $1 \mathrm{e}-11$ & $1 \mathrm{e}-11$ & $\mathrm{~m}^{2} / \mathrm{s}$ \\
$S_{\mathrm{a}}$ & Signalling coefficient for Wnt/B-catenin & $8 \mathrm{e}-1$ & $8 \mathrm{e}-1$ & $8 \mathrm{e}-1$ & $1 \mathrm{e}-3$ & $\mathrm{~s}^{-1}$ \\
$R_{\mathrm{a}}$ & Reaction coefficient for Wnt//3-catenin & 0.08 & 0.08 & 0.08 & 0.08 & $\mathrm{~s}^{-1}$ \\
$D_{\mathrm{b}}$ & Diffusive coefficient for Fgf & $1 \mathrm{e}-11$ & $1 \mathrm{e}-11$ & $1 \mathrm{e}-11$ & $1 \mathrm{e}-11$ & $\mathrm{~m}^{2} / \mathrm{s}$ \\
$P_{\mathrm{b}}$ & Production coefficient for Fgf & $8 \mathrm{e}-2$ & $8 \mathrm{e}-2$ & $8 \mathrm{e}-2$ & $8 \mathrm{e}-2$ & $\mathrm{~s}^{-1}$ \\
$R_{\mathrm{b}}$ & Reaction coefficient for Fgf & $5 \mathrm{e}-1$ & $5 \mathrm{e}-3$ & $5 \mathrm{e}-1$ & $5 \mathrm{e}-1$ & $\mathrm{~s}^{-1}$ \\
$P_{\mathrm{c}}$ & Production coefficient for $c x c r 4 b$ & $0.2 \mathrm{e}-3$ & $0.2 \mathrm{e}-3$ & $0.2 \mathrm{e}-3$ & $0.2 \mathrm{e}-3$ & $\mathrm{~s}^{-1}$ \\
$R_{\mathrm{c}}$ & Reaction coefficient for $c x c r 4 b$ & $2 \mathrm{e}-4$ & $2 \mathrm{e}-5$ & $2 \mathrm{e}-4$ & $2 \mathrm{e}-4$ & $\mathrm{~s}^{-1}$ \\
$P_{\mathrm{d}}$ & Production coefficient for $c x c r 7 b$ & $0.1 \mathrm{e}-3$ & $0.1 \mathrm{e}-3$ & $0.1 \mathrm{e}-3$ & $0.1 \mathrm{e}-3$ & $\mathrm{~s}^{-1}$ \\
$R_{\mathrm{d}}$ & Reaction coefficient for $c x c r 7 b$ & $1 \mathrm{e}-4$ & $1 \mathrm{e}-4$ & $1 \mathrm{e}-4$ & $1 \mathrm{e}-4$ & $\mathrm{~s}^{-1}$ \\
\hline
\end{tabular}

corresponds to the expression of the molecule or chemokine, while a value of 0 (blue) indicates that the molecule or chemokine is not expressed. Our numerical results agree with the experimental observations (Aman and Piotrowski 2008) as the same patterns for Wnt/ß-catenin, FGF, $c x c r 4 b$ and $c x c r 7 b$ are obtained for each mutant.

We now proceed with the implementation of the mechanical framework in the model. 


\begin{tabular}{|c|c|c|c|c|c|c|}
\hline Embryo & $\begin{array}{l}\text { Wnt/B-catenin } \\
\text { concentration }\end{array}$ & $\begin{array}{c}\text { FGF } \\
\text { concentration }\end{array}$ & $\begin{array}{c}\text { cxcr } 4 b \\
\text { concentration }\end{array}$ & $\begin{array}{c}\text { cxcr } 7 \mathrm{~b} \\
\text { concentration }\end{array}$ & $\begin{array}{l}\text { Total } \\
\text { displacement of } \\
\text { the 'bow' of the } \\
\text { LLP }(\mu \mathrm{m})\end{array}$ & $\begin{array}{l}\text { Average stress } \\
\text { over the LLP } \\
(\mathrm{Pa})\end{array}$ \\
\hline$w t$ & & & & & 2480 & 583 \\
\hline$a p c$ & & & & & 193 & 1236 \\
\hline SU5402 & & & & & 415 & 1068 \\
\hline$d k k 1$ & & & & & 3170 & 781 \\
\hline
\end{tabular}

0

Fig. 4 Numerical results for the four mutants at the end of the simulations ( $t=1$ day) (Sect. 3.2). Columns from 2 to 5 show the molecule and chemokine normalized concentrations over the LLP, which may vary from 0 (blue) to 1 (red) (Sect. 3.1). Columns 6 and 7 show the values for the total displacement of the 'bow' of the LLP and the average stress over the whole population (Sect. 3.2) (Color figure online)

\section{$3.2 c x c r 4 b-c x c r 7 b$ Polarization Regulates the Efficient Migration of the LLP}

According to the molecular and chemokine patterns described in Sect. 3.1, the wt and the mutant embryos show the following specific migration behaviour when experimentally observed (Aman and Piotrowski 2008):

- in the $w t$ embryo, the LLP travels at constant speed from the head towards the tail along the trunk, which results in what is called the normal migration of the population;

- the apc and SU5402 embryos show a very similar behaviour to each other. In fact, the primordium stalls due to the unpolarization of the two chemokines $c x c r 4 b$ and $c x c r 7 b$, which is led by the uniform and unpolarized diffusion of $\mathrm{Wnt} / \beta$-catenin and FGF throughout the LLP respectively in the apc and the SU5402 embryo;

- finally, in the $d k k 1$ embryo the LLP migration is not affected since the $c x c r 4 b-$ $c x c r 7 b$ spatial polarization is maintained.

Therefore, our conclusion is that for the LLP to migrate in an efficient and synchronized manner as is observed for the $w t$ and the $d k k 1$ embryos, Wnt/ß-catenin-FGF polarity may occur (i.e. $w t$ embryo) or not (i.e. $d k k 1$ embryo), while $c x c r 4 b-c x c r 7 b$ polarity is a necessary condition.

In the present paper, the uncoordinated and the coordinated movements of the cells within the population have been described in Sect. 2.3. In the former case, very similar to the random migration proposed in our previous work (Allena et al. 2013), all the cells are active and migrate at their own pace, which leads to an unsynchronized migration. In the latter case, once the polarization of the two chemokines, $c x c r 4 b$ and $c x c r 7 b$, is achieved, a wave progressively covers the LLP and activates one by one the 
rows of cells, which start to migrate in phase. The shift between the uncoordinated and coordinated migration is observable for the $w t$ and the $d k k l$ embryos. In fact, $c x c r 4 b-c x c r 7 b$ polarization is reached at around 22 and $23 \mathrm{hpf}$, respectively, for the former and for the latter embryo (Movies 1 and 4, respectively). However, for the apc and the SU5402 embryos, the cells move in an unsynchronized manner throughout the simulation (Movies 2 and 3, respectively).

Such a cellular behaviour is also reflected in terms of distance covered and stress state inside the LLP. First, as in our previous work (Allena et al. 2013), we found a correspondence between the efficiency of the cell cohort migration and the stress distribution within the population: normal and efficient migration coincides with low stresses within the LLP. Actually, the $w t$ and $d k k l$ embryos are the most efficient and they migrate for 2,480 and $3,170 \mu \mathrm{m}$ (displacement calculated at the 'bow' of the LLP), respectively, and the average stress has been found equal to 583 and $781 \mathrm{~Pa}$, respectively (Fig. 4, columns 6 and 7). Such values are on the same order as those found experimentally by previous authors (Serra-Picamal et al. 2012; Tambe et al. 2011; Trepat et al. 2009). However, the apc and SU5042 embryos only migrate a distance of 193 and $415 \mu \mathrm{m}$ (displacement calculated at the 'bow' of the LLP), respectively, and the average stress is equal to 1,236 and 1,068 Pa, respectively (Fig. 4, columns 6 and 7).

Second, the switch between uncoordinated and coordinated migration coincides with the rearrangement of the principal directions of the stresses. As far as the cells migrate at their own pace, the principal stresses are oriented in different directions within the population, while they are aligned with the direction of migration as soon as the cells start coordinating their movement.

Third, while during the uncoordinated migration all the cells generate high stresses, during the coordinated migration, only the central cells are those which develop the highest stresses due to the neighbouring constrictions.

\subsection{What About Cell Leadership?}

According to the experimental observations in Aman and Piotrowski (2008), the polarity between $c x c r 4 b-c x c r 7 b$ seems to be biochemically necessary for normal migration. By assuming this is the case, in the previous set of simulations such a polarity led to a proper inter-synchronization of all the cells within the LLP (i.e. $w t$ and $d k k l$ embryos, Movies 1 and 4). However, one of the main questions that has been experimentally addressed, but still remains partially unanswered, is whether all the cells, or only a few of them, sense such a polarity acting as leader cells and start migrating in a coordinated manner.

Therefore, we have numerically explored if and how, once the $c x c r 4 b-c x c r 7 b$ polarity has been established, the density of coordinated cells within the LLP may affect the global behaviour of the population. To do so, a new set of simulations has been run and four configurations have been tested for which the coordinated migration involves (i) only cells in the first row $\left(r_{18}\right)$, (ii) only cells in the first two rows $\left(r_{18}\right.$ and $\left.r_{17}\right)$, (iii) only cells in the first three rows $\left(r_{18}, r_{17}\right.$ and $\left.r_{16}\right)$ and (iv) cells inside the frontal region, $\Omega_{\text {front }}$, of the LLP. 


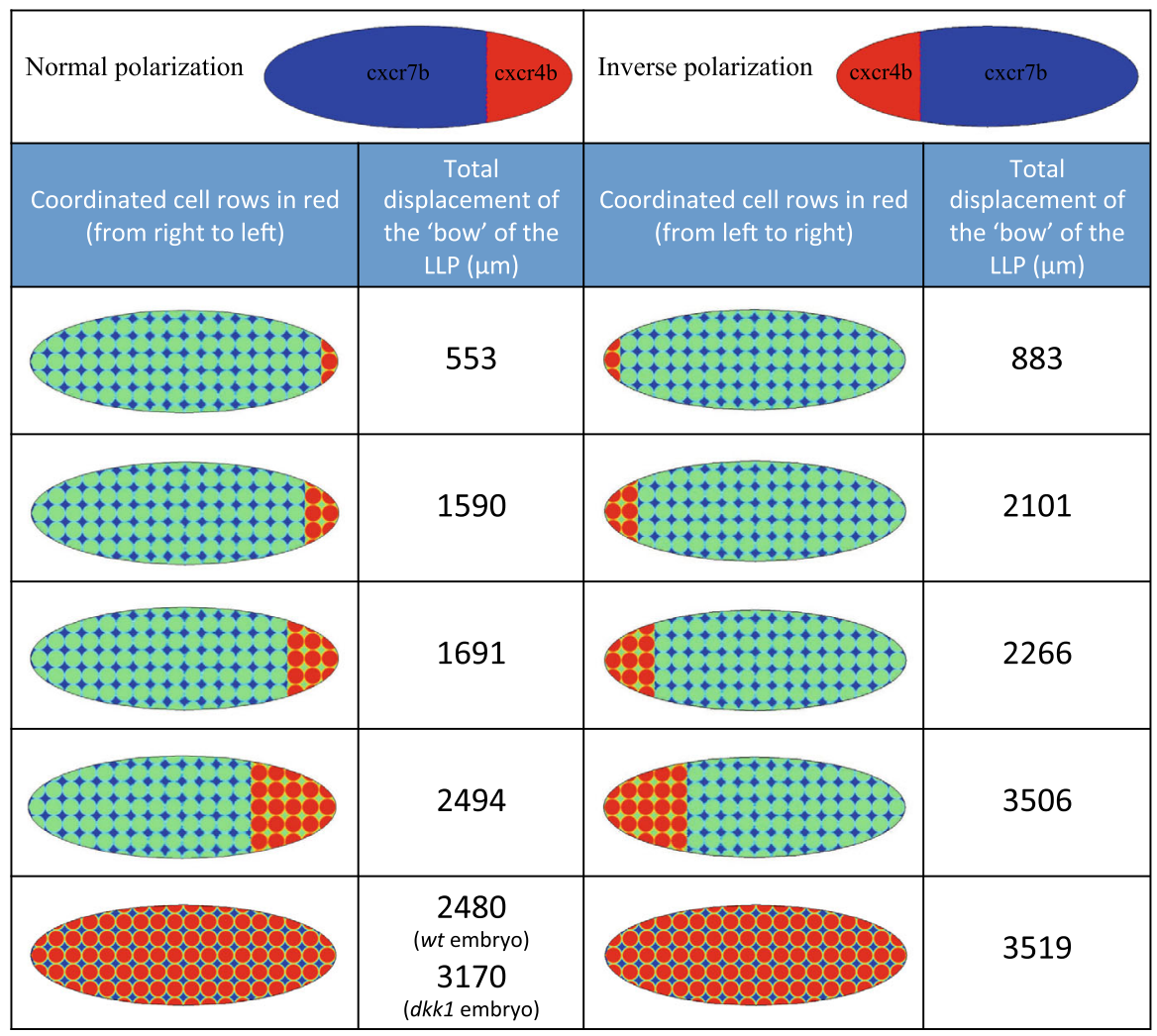

Fig. 5 Numerical results at the end of the simulations ( $t=1$ day) for the case of normal (columns 1 and 2) and inverse (column 3 and 4) cxcr $4 b-c x c r 7 b$ polarization (Sect. 3.3). Columns 1 and 3 show in red the coordinated cell rows. In columns 2 and 4, the values of the total displacement of the 'bow' of the LLP are reported (Color figure online)

By analysing the results in terms of efficiency of the LLP (i.e. distance covered over 1 day by the 'bow' of the LLP) (column 2 in Fig. 5), we observe that when only one row of cells is coordinated, the total displacement of the population is about $553 \mu \mathrm{m}$, which is larger than that of a continuous uncoordinated migration (193 and $415 \mu \mathrm{m}$ for the apc and the SU5402 embryos, respectively), but much smaller than that reached during normal migration $(2,480$ and $3,170 \mu \mathrm{m}$ for the $w t$ and the $d k k 1$ embryos, respectively). If one or two more rows also coordinate their movement, the global efficiency increases, but the total displacement of the LLP is still smaller than in the case of normal migration (1,590 and 1,691 $\mu \mathrm{m}$, respectively).

However, when all the cell rows inside the frontal region of the LLP are coordinated, the population is able to migrate over $2,494 \mu \mathrm{m}$, which is very close to the displacement of the $w t$ and $d k k l$ embryos. Such outcomes confirm that a minimal level of intersynchronization between the cells is necessary for the LLP to be efficient, as we have demonstrated in our previous work (Allena et al. 2013), but also that a small portion of 
competent cells is required to steer the population (Kabla 2011; Vitorino and Meyer 2008).

In in vivo situations, leader cells are usually found at free boundaries of the population to direct the motion and to "dig up the road" within the surrounding cells. Although this second function must play a fundamental role during LLP migration, we have investigated whether the position of the leader cells may affect the global behaviour of the system. A third set of simulations has been run for which $c x c r 4 b$ $c x c r 7 b$ polarity has been reversed (i.e. $\Omega_{\text {front }}$ and $\Omega_{\text {rear }}$ are reversed so that the "stern" and the "bow" of the LLP correspond to the front and rear respectively), but the direction of migration is still the same. Consequently, the leader cells are located at the "stern" of the LLP, and the synchronization of the motion occurs from the "stern" towards the "bow" of the population. As for the previous set of simulations, four configurations have been analysed for which coordinated migration involves (i) only one row of cells $\left(r_{1}\right)$, (ii) two rows of cells $\left(r_{1}\right.$ and $\left.r_{2}\right)$, (iii) three rows of cells $\left(r_{1}, r_{2}\right.$ and $r_{3}$ ) and (iv) the rows inside the $\Omega_{\text {front }}$ domain. The results are shown in column 4 of Fig. 5. Surprisingly, the same conclusions as for the second set of simulations (column 2, Fig. 5) can be drawn regarding the efficiency of the migration. In fact, from a mechanical point of view, as far as a minimal number of cells within the population are able to coordinate their movement, whether they are at the front or at the back does not influence the global effectiveness of the system (Couzin et al. 2005; Kabla 2011). As mentioned in Sect. 1.1, it has been experimentally observed that normal migration is not only triggered by $c x c r 4 b-c x c r 7 b$ polarity, it also follows SDF-1 expression, which is controlled by $c x c r 4 b$ at the leading edge (Haas and Gilmour 2006). Although further measurements are needed to confirm such a hypothesis, our numerical results clearly show that a further spatial signal is required for the leader cells to be located at the frontal edge of the LLP, and SDF-1 might be a good candidate. This hypothesis seems also to be plausible considering that the cells at the "bow" of the LLP might be able "to see" and sense the environment in front of them and therefore to choose and adjust their path accordingly.

Therefore, the pioneer cells would be simultaneously responsible for regulating the inter-synchronization, which is the necessary condition for normal migration, and directing migration towards the tail of the animal.

\section{Conclusions}

Here, we have proposed a 2D finite element model to simulate the collective migration of the LLP. The population is modelled as a continuum with embedded discrete motile cells, which are viscoelastic and able to undergo large deformations (Sect. 2.1). Both the molecular and the mechanical frameworks of the system have been considered. The former takes into account Wnt/ß-catenin and FGF signalling as well as $c x c r 4 b$ and $c x c r 7 b$ expression, which have been described through specific reactiondiffusion equations (Sect. 2.2). For the latter, as in the previous works of the first author (Allena 2013; Allena and Aubry 2012; Allena et al. 2013), we have employed the decomposition of the deformation gradient to describe both the active (i.e. protrusion and contraction) and the elastic (i.e. generated by the interaction with the ECM) 
deformations (Sect. 2.3). Additionally, the active deformations are closely coupled with the molecular framework of the system. First, the intensity of the protrusioncontraction movement depends on the $c x c r 4 b$ concentration. Second, the intrasynchronization between the active deformations and the adhesion forces necessary to move forward is regulated by $c x c r 4 b-c x c r 7 b$ polarity. In fact, until $c x c r 4 b-c x c r 7 b$ polarity is achieved, the cells migrate in an uncoordinated manner, while they start to synchronize their movement as soon as the two chemokines are correctly expressed.

In order to validate such a model, we have considered four different mutants as presented in Aman and Piotrowski (2008): the wt, apc, SU5402 and dkk1 embryos (Sect. 3.1). Each one of these embryos shows a specific molecular pattern, which influences the global motion of the LLP. On the one hand, the $w t$ and the $d k k l$ embryos migrate in a normal way due to the $c x c r 4 b-c x c r 7 b$ polarity, which allows the cells to coordinate their movement. On the other hand, the apc and the SU5402 embryos stall and are not very efficient in terms of distance covered. By coupling both the molecular and the mechanical frameworks, our model is able to simulate such behaviours and the results are in agreement with the experimental observations (Sect. 3.2).

By assuming that $c x c r 4 b-c x c r 7 b$ polarity is the required molecular condition for normal migration, we have theoretically investigated the role of the leader cells and their position within the population. By running two new series of simulations, we have found that: (i) a small portion of coordinated cells is necessary (Allena et al. 2013) and sufficient (Vitorino and Meyer 2008) to induce the normal and efficient migration of the LLP and (ii) from a mechanical point of view, once the previous condition is ensured, the position of the leader cells inside the population does not influence the global efficiency of the LLP migration.

Therefore, the general assumption by which leader cells in the LLP are located at the frontal edge of the population can only be sustained if, besides $c x c r 4 b-c x c r 7 b$ polarity, which seems to trigger the inter-synchronization, leader cells respond to a further spatial feedback in control of their position.

Such an outcome could confirm the experimental observations according to which the normal migration of the LLP appears to follow a line of the chemokine SDF-1 along the embryo trunk, which depends on the expression of $c x c r 4 b$ in the leading edge (Haas and Gilmour 2006). Thus, cells at the front of the LLP expressing $c x c r 4 b$ might be responsible for sensing the SDF-1 gradient and for directing migration.

The present model has two main limitations. First, no external signal, such as a SDF-1 gradient, has been considered and only molecular processes internal to the LLP have been taken into account. Therefore, the model could be extended by introducing an ordinary differential equation to control both the intensity and the direction of the external source (Allena 2013; Allena and Aubry 2012). By doing this, it would be possible to evaluate the influence of such a further spatial feedback on the global efficiency of the LLP as well as on the inter-synchronization between the cells. Second, no interaction between the LLP and the surrounding ECM and cells, which may play an important role during the whole migration, has been considered. These extensions will be presented in future research which aims to better understand how LLP is able to structurally modify its environment in order to migrate through it. 
Acknowledgments This work was initiated and partially completed while Rachele Allena was a visitor to the Mathematical Institute, Oxford. The authors are grateful to Dr. Tatjana Piotrowski and Pr. Denis Aubry for useful discussions.

\section{Appendix}

\section{LLP Geometry}

The cell network $\Omega_{n}$ is defined by a characteristic function $h_{n}(\boldsymbol{p})$ as follows:

$$
h_{n}(\boldsymbol{p})=\left\{\begin{array}{l}
1 \text { if }\left\|\boldsymbol{p}-2 \cdot r_{\mathrm{c}} \cdot \operatorname{round}\left(p_{x}\right) \boldsymbol{i}_{x}-2 \cdot r_{\mathrm{c}} \cdot \operatorname{round}\left(p_{y}\right) \boldsymbol{i}_{y}\right\|<r_{c}^{2} \\
0 \text { otherwise }
\end{array}\right.
$$

with round being the classical integer function and $\boldsymbol{p}=\left(p_{x}, p_{y}\right)$ the initial position of any particle of the system .

The ECM domain $\Omega_{\mathrm{ECM}}$ is identified by the characteristic function $h_{\mathrm{ECM}}(\boldsymbol{p})$ which reads

$$
h_{\mathrm{ECM}}(\boldsymbol{p})=1-h_{n}(\boldsymbol{p}) .
$$

Each cell inside the population is denoted by $c(i, j)$ where the indices $i$ and $j$ vary as follows:

$$
\left\{\begin{array}{l}
1 \leq i \leq N_{\mathrm{c}}=i_{\max } \\
1 \leq j \leq n_{\mathrm{c}}(i)=n_{\mathrm{c}, \max } \sqrt{1-\left(\frac{2 i-1}{N_{\mathrm{c}}}\right)^{2}}
\end{array}\right.
$$

with $N_{\mathrm{c}}=\frac{L}{r_{\mathrm{c}}}, i_{\max }=18$ and $n_{\mathrm{c}, \max }=\frac{l}{r_{\mathrm{c}}}$ being the number of cells along the two axes of the ellipse (Fig. 2b, c).

The domain $\Omega_{\mathrm{c}_{i, j}}$ occupied by each cell $c(i, j)$ is defined through a characteristic function as follows

$$
h_{\mathrm{c}_{i, j}}(\boldsymbol{p})= \begin{cases}1 & \text { if }\left\|\boldsymbol{p}-\boldsymbol{c}_{i, j}\right\|<r_{c}^{2} \\ 0 & \text { otherwise }\end{cases}
$$

Each cell is equipped with a frontal $\partial \Omega_{\mathrm{sf}_{i, j}}$ and a rear $\partial \Omega_{\mathrm{sr}_{i, j}}$ adhesion region (Fig. $2 \mathrm{~d})$ described, respectively, by two characteristic functions

$$
\begin{aligned}
& h_{\mathrm{sf}_{i, j}}(\boldsymbol{p})= \begin{cases}1 & \text { if }\left(\boldsymbol{p}-\boldsymbol{c}_{i, j}, \boldsymbol{i}_{x}\right)>l_{\mathrm{f}} \\
0 & \text { otherwise }\end{cases} \\
& h_{\mathrm{sr}_{i, j}}(\boldsymbol{p})= \begin{cases}1 & \text { if }\left(\boldsymbol{p}-\boldsymbol{c}_{i, j}, \boldsymbol{i}_{x}\right)<-l_{r} \\
0 & \text { otherwise }\end{cases}
\end{aligned}
$$

where $(\boldsymbol{a}, \boldsymbol{b})$ defines the scalar product and $l_{\mathrm{f}}$ and $l_{\mathrm{r}}$ are the distances of $\boldsymbol{c}_{i, j}$ from the frontal and rear adhesion surfaces, respectively. 
The ellipse is divided into cell rows $r(i)$ (Fig. 2b), which are numbered, similarly to the single cells, from the "stern" (left) to the "bow" (right) of the ellipse ( $1 \leq i \leq$ $N_{\mathrm{c}}=i_{\max }$ ) (Fig. 2c) and are defined through a characteristic function as

$$
h_{r_{i}}(\boldsymbol{p})=h_{n}(\boldsymbol{p}) \begin{cases}1 & \text { if }\left(p_{x}-c_{i, j_{x}}\right)<r_{c} \\ 0 & \text { otherwise. }\end{cases}
$$

Leading and Trailing Edge of the LLP

The Wnt/ß-catenin-FGF network is mainly based on the spatial polarization of the LLP. We define the leading, $\Omega_{\text {front }}$, and the trailing, $\Omega_{\text {rear }}$, edges of the LLP through the characteristic functions $h_{\text {front }}$ and $h_{\text {rear }}$, respectively, as follows:

$$
\begin{aligned}
h_{\text {front }} & = \begin{cases}1 & \text { if } p_{x}>p_{x 0} \\
0 & \text { otherwise }\end{cases} \\
h_{\text {rear }} & = \begin{cases}1 & \text { if } p_{x}<p_{x 0} \\
0 & \text { otherwise }\end{cases}
\end{aligned}
$$

where $p_{x 0}$ is the axial coordinate defining the boundary between the leading and the trailing edges.

\section{Description of Mutants}

In the following, we define the reaction-diffusion equations that have been used to describe the molecular and chemokine patterns specific to each mutant as mentioned in Sect. 2.2.

- apc embryo

$$
\begin{aligned}
& \frac{\partial[W]}{\partial t}=\underbrace{D_{a} \nabla^{2}[W]}_{\text {diffusion }}+\underbrace{S_{a}[W](1-[W])}_{\text {signalling }}-\underbrace{R_{\mathrm{a}}[W][F]}_{\text {reaction by dkk1 }} \\
& \frac{\partial[F]}{\partial t}=\underbrace{D_{\mathrm{b}} \nabla^{2}[F]}_{\text {diffusion }}+\underbrace{P_{\mathrm{b}}[W](1-[F])}_{\text {production }}-\underbrace{R_{\mathrm{b}}[F][W]}_{\text {reaction by sef }} \\
& \frac{\partial\left[c_{4}\right]}{\partial t}=\underbrace{P_{\mathrm{c}}\left[c_{4}\right]\left(1-\left[c_{4}\right]\right)}_{\text {production }}-\underbrace{R_{\mathrm{c}}\left[c_{4}\right][F]}_{\text {reaction by Fgf }} \\
& \frac{\partial\left[c_{7}\right]}{\partial t}=\underbrace{P_{\mathrm{d}}\left[c_{7}\right]\left(1-\left[c_{7}\right]\right)}_{\text {production }}-\underbrace{R_{\mathrm{d}}\left[c_{7}\right][W]}_{\text {reaction by Wnt }}
\end{aligned}
$$

- SU5402 embryo

$$
\frac{\partial[W]}{\partial t}=\underbrace{D_{\mathrm{a}} \nabla^{2}[W]}_{\text {diffusion }}+\underbrace{S_{\mathrm{a}}[W](1-[W]) h_{\text {front }}}_{\text {signalling }}-\underbrace{R_{\mathrm{a}}[W][F] h_{\text {rear }}}_{\text {reaction by dkk1 }}
$$




$$
\begin{aligned}
& \frac{\partial[F]}{\partial t}=\underbrace{D_{\mathrm{b}} \nabla^{2}[F]}_{\text {diffusion }}-\underbrace{R_{\mathrm{b}}[F][W] h_{\text {front }}}_{\text {reaction by sef }} \\
& \frac{\partial\left[c_{4}\right]}{\partial t}=\underbrace{P_{\mathrm{c}}\left[c_{4}\right]\left(1-\left[c_{4}\right]\right)}_{\text {production }}-\underbrace{R_{\mathrm{c}}\left[c_{4}\right][F]}_{\text {reaction } b y F g f} \\
& \frac{\partial\left[c_{7}\right]}{\partial t}=\underbrace{P_{\mathrm{d}}\left[c_{7}\right]\left(1-\left[c_{7}\right]\right)}_{\text {production }}-\underbrace{R_{\mathrm{d}}\left[c_{7}\right][W]}_{\text {reaction by } W n t}
\end{aligned}
$$

$-d k k 1$ embryo

$$
\begin{aligned}
& \frac{\partial[W]}{\partial t}=\underbrace{D_{\mathrm{a}} \nabla^{2}[W]}_{\text {diffusion }}+\underbrace{S_{\mathrm{a}}[W](1-[W]) h_{\text {front }}}_{\text {signalling }}-\underbrace{R_{\mathrm{a}}[W][F]}_{\text {reaction by } d k k 1} \\
& \frac{\partial[F]}{\partial t}=\underbrace{D_{\mathrm{b}} \nabla^{2}[F]}_{\text {diffusion }}+P_{\mathrm{b}}[W](1-[F])-\underbrace{R_{\mathrm{b}}[F][W] h_{\text {front }}}_{\text {reaction by } s e f} \\
& \frac{\partial\left[c_{4}\right]}{\partial t}=\underbrace{P_{\mathrm{c}}\left[c_{4}\right]\left(1-\left[c_{4}\right]\right)}_{\text {production }}-\underbrace{R_{\mathrm{c}}\left[c_{4}\right][F]}_{\text {reaction by } F g f} \\
& \frac{\partial\left[c_{7}\right]}{\partial t}=\underbrace{P_{\mathrm{d}}\left[c_{7}\right]\left(1-\left[c_{7}\right]\right)}_{\text {production }}-\underbrace{R_{\mathrm{d}}\left[c_{7}\right][W]}_{\text {reaction by } W n t}
\end{aligned}
$$

\section{Constitutive Model}

As mentioned in Sect. 2.3, the behaviour of the cells is described through a generalized viscoelastic 2D Maxwell model (Allena 2013; Allena and Aubry 2012).

The Cauchy stress, $\sigma$, is assumed to be the sum of the solid $\left(\sigma_{\mathrm{s}}\right)$ and the fluid $\left(\sigma_{\mathrm{f}}\right)$ Cauchy stresses, while the deformation gradient $\boldsymbol{F}$ is equal to the solid $\left(\boldsymbol{F}_{\mathrm{S}}\right)$ and the fluid $\left(\boldsymbol{F}_{\mathrm{f}}\right)$ deformation gradients.

The decomposition of the deformation gradient (Allena et al. 2010; Lubarda 2004) is used to describe the solid deformation tensor, $\boldsymbol{F}_{\mathrm{s}}$, which is then given by

$$
\boldsymbol{F}_{\mathrm{s}}=\boldsymbol{F}_{\mathrm{se}} \boldsymbol{F}_{\mathrm{sa}}
$$

where $\boldsymbol{F}_{\text {se }}$ is the elastic deformation tensor responsible for the stress generation and $\boldsymbol{F}_{\text {sa }}$ is the active deformation tensor responsible for the pulsating movement (protrusioncontraction) of each cell. Similarly, the fluid deformation tensor $\boldsymbol{F}_{\mathrm{f}}$ is the multiplicative decomposition of the fluid elastic $\left(\boldsymbol{F}_{\mathrm{fe}}\right)$ and the fluid viscoelastic $\left(\boldsymbol{F}_{\mathrm{fv}}\right)$ gradients.

Both the solid $\sigma_{\mathrm{se}}$ and the fluid elastic $\sigma_{\mathrm{fe}}$ Cauchy stresses are given by isotropic hyperelastic models $\overline{\boldsymbol{\sigma}}_{\text {se }}$ and $\overline{\boldsymbol{\sigma}}_{\text {fe }}$, respectively, as

$$
\begin{aligned}
& \boldsymbol{\sigma}_{\mathrm{se}}=\overline{\boldsymbol{\sigma}}_{\mathrm{se}}\left(\boldsymbol{e}_{\mathrm{se}}\right) \\
& \boldsymbol{\sigma}_{\mathrm{fe}}=\overline{\boldsymbol{\sigma}}_{\mathrm{fe}}\left(\boldsymbol{e}_{\mathrm{fe}}\right)
\end{aligned}
$$


with $\boldsymbol{e}_{\mathrm{se}}$ and $\boldsymbol{e}_{\mathrm{fe}}$ the Euler-Almansi deformation tensors for the solid elastic and the fluid elastic phases, respectively. Additionally, $\sigma_{\mathrm{fe}}$ has to be expressed in the actual configuration according to the multiplicative decomposition described above. Finally, the deformation rate $\dot{\boldsymbol{e}}_{\mathrm{fv}}$ is related to the deviator part of the fluid viscous stress $\boldsymbol{\sigma}_{\mathrm{fv}}^{D}$ as follows:

$$
\dot{\boldsymbol{e}}_{\mathrm{fv}}=\frac{\sigma_{\mathrm{fv}}^{D}}{\mu_{\mathrm{fv}}}
$$

where $\mu_{\mathrm{fv}}$ is the viscosity and the dot is the derivative with respect to time.

\section{Coordinated and Uncoordinated Migration}

The characteristic functions $h_{\mathrm{c}}$ and $h_{\mathrm{uc}}$ are expressed as follows

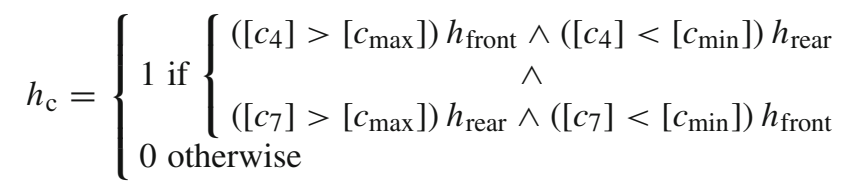

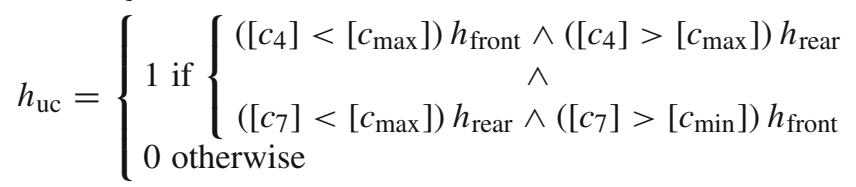

with $\wedge$ being the Boolean operator AND and $c_{\max }$ and $c_{\min }$ being two thresholds fixed here to 0.9 and 0.2 , respectively.

The terms $e_{a, c}$ and $e_{a, u c}$ describe the cyclic deformation of protrusion-contraction, and they read

$$
\begin{aligned}
e_{a, c} & =\frac{\left[c_{4}\right]}{\alpha_{c}} \sin \left(2 \pi \frac{t-\frac{T}{2}\left(i_{\max }-i\right)}{T}\right) h_{r_{i}}(\boldsymbol{p}) h_{\text {wave }}(\boldsymbol{p}, t) \\
e_{a, u c} & =\frac{\left[c_{4}\right]}{\alpha_{u c_{i j}}} \sin \left(2 \pi \frac{t}{T_{u c_{i j}}}\right)
\end{aligned}
$$

where $t$ is time.

For the coordinated migration, $\alpha_{c}$ is set to 2 and $T$ indicates the duration of a migration period which has been fixed here to 60 s (Allena and Aubry 2012; Dong et al. 2002). Additionally, a wave progressively covers the LLP from the "bow" to the "stern" to activate, one by one, the cell row $r(i)$ with a velocity equal to $\frac{2 t}{T}$. The wave is expressed by the characteristic function $h_{\text {wave }}(\boldsymbol{p}, t)$ as follows:

$$
h_{\text {wave }}(\boldsymbol{p}, t)=\left\{\begin{array}{l}
1 \text { if }\left(2 L-r_{c}\right)-p_{x}-2 r_{c} \frac{2 t}{T}<0 \\
0 \text { otherwise. }
\end{array}\right.
$$


For the uncoordinated migration, $\alpha_{u c_{i j}}$ and $T_{u c_{i j}}$ may vary between 0 and 1 and between 60 and $120 \mathrm{~s}$, respectively, for each cell $c(i, j)$.

\section{References}

Allena R (2013) Cell migration with multiple pseudopodia: temporal and spatial sensing models. Bull Math Biol 75(2):288-316. doi:10.1007/s11538-012-9806-1

Allena R, Aubry D (2012) 'Run-and-tumble' or 'look-and-run'? A mechanical model to explore the behavior of a migrating amoeboid cell. J Theor Biol 306:15-31. doi:10.1016/j.jtbi.2012.03.041

Allena R, Aubry D, Sharpe J (2013) On the mechanical interplay between intra- and inter-synchronization during collective cell migration: a numerical investigation. Bull Math Biol 75(12):2575-2599. doi:10. 1007/s11538-013-9908-4

Allena R, Mouronval A-S, Aubry D (2010) Simulation of multiple morphogenetic movements in the Drosophila embryo by a single 3D finite element model. J Mech Behav Biomed Mater 3(4):313323. doi:10.1016/j.jmbbm.2010.01.001

Aman A, Piotrowski T (2008) Wnt/beta-catenin and Fgf signaling control collective cell migration by restricting chemokine receptor expression. Dev cell 15(5):749-761. doi:10.1016/j.devcel.2008.10. 002

Aman A, Piotrowski T (2009) Multiple signaling interactions coordinate collective cell migration of the posterior lateral line primordium. Cell Adhes Migr 3(4):365-368

Aman A, Piotrowski T (2011) Cell-cell signaling interactions coordinate multiple cell behaviors that drive morphogenesis of the lateral line. Cell Adhes Migr 5(6):499-508. doi:10.4161/cam.5.6.19113

Anand RJ, Leaphart CL, Mollen KP, Hackam DJ (2007) The role of the intestinal barrier in the pathogenesis of necrotizing enterocolitis. Shock (Augusta, Ga) 27(2):124-133. doi:10.1097/01.shk.0000239774. 02904.65

Arciero JC, Mi Q, Branca MF, Hackam DJ, Swigon D (2011) Continuum model of collective cell migration in wound healing and colony expansion. Biophys J 100(3):535-543. doi:10.1016/j.bpj.2010.11.083

Bausch AR, Möller W, Sackmann E (1999) Measurement of local viscoelasticity and forces in living cells by magnetic tweezers. Biophys J 76(1 Pt 1):573-579

Couzin ID, Krause J, Franks NR, Levin SA (2005) Effective leadership and decision-making in animal groups on the move. Nature 433(7025):513-516. doi:10.1038/nature03236

Dambly-Chaudière C, Cubedo N, Ghysen A (2007) Control of cell migration in the development of the posterior lateral line: antagonistic interactions between the chemokine receptors CXCR4 and CXCR7/RDC1. BMC Dev Biol 7:23. doi:10.1186/1471-213X-7-23

David NB, Sapède D, Saint-Etienne L, Thisse C, Thisse B, Dambly-Chaudière C, Ghysen A (2002) Molecular basis of cell migration in the fish lateral line: role of the chemokine receptor CXCR4 and of its ligand, SDF1. Proc Natl Acad Sci 99(25):16297-16302. doi:10.1073/pnas.252339399

Di Costanzo E, Natalini R, Preziosi L (2014) A hybrid mathematical model for self-organizing cell migration in the zebrafish lateral line. J Math Biol. doi:10.1007/s00285-014-0812-9

Dong C, Slattery MJ, Rank BM, You J (2002) In vitro characterization and micromechanics of tumor cell chemotactic protrusion, locomotion, and extravasation. Ann Biomed Eng 30(3):344-355

Drury JL, Dembo M (2001) Aspiration of human neutrophils: effects of shear thinning and cortical dissipation. Biophys J 81(6):3166-3177

Friedl P, Gilmour D (2009) Collective cell migration in morphogenesis, regeneration and cancer. Nat Rev Mol Cell Biol 10(7):445-457. doi:10.1038/nrm2720

Fukui Y, Uyeda TQP, Kitayama C, Inoué S (2000) How well can an amoeba climb? Proc Natl Acad Sci 97(18):10020-10025. doi:10.1073/pnas.97.18.10020

Gamba L, Cubedo N, Ghysen A, Lutfalla G, Dambly-Chaudière C (2010) Estrogen receptor ESR1 controls cell migration by repressing chemokine receptor CXCR4 in the zebrafish posterior lateral line system. Proc Natl Acad Sci 107(14):6358-6363. doi:10.1073/pnas.0909998107

Gompel N, Cubedo N, Thisse C, Thisse B, Dambly-Chaudière C, Ghysen A (2001) Pattern formation in the lateral line of zebrafish. Mech Dev 105(1-2):69-77

Graner, Glazier (1992) Simulation of biological cell sorting using a two-dimensional extended Potts model. Phys Rev Lett 69(13):2013-2016

Haas P, Gilmour D (2006) Chemokine signaling mediates self-organizing tissue migration in the zebrafish lateral line. Dev Cell 10(5):673-680. doi:10.1016/j.devcel.2006.02.019 
Holzapfel GA (2000) Nonlinear solid mechanics: a continuum approach for engineering, 1st edn. Wiley, Hoboken

Ilina O, Friedl P (2009) Mechanisms of collective cell migration at a glance. J Cell Sci 122(18):3203-3208. doi: $10.1242 /$ jcs. 036525

Kabla AJ (2011) Collective cell migration: leadership, invasion and segregation. arXiv:1108.4286 [physics, q-bio]. Retrieved from http://arxiv.org/abs/1108.4286

Laurent VM, Kasas S, Yersin A, Schäffer TE, Catsicas S, Dietler G, Meister J-J et al (2005) Gradient of rigidity in the lamellipodia of migrating cells revealed by atomic force microscopy. Biophys $\mathrm{J}$ 89(1):667-675. doi:10.1529/biophysj.104.052316

Lecaudey V, Cakan-Akdogan G, Norton WHJ, Gilmour D (2008) Dynamic Fgf signaling couples morphogenesis and migration in the zebrafish lateral line primordium. Development (Cambridge, England) 135(16):2695-2705. doi:10.1242/dev.025981

López-Schier H (2010) Fly fishing for collective cell migration. Curr Opin Genet Dev 20(4):428-432. doi:10.1016/j.gde.2010.04.006

Lubarda V (2004) Constitutive theories based on the multiplicative decomposition of deformation gradient: thermoelasticity, elastoplasticity, and biomechanics. Appl Mech Rev 57(2):95-109

Nechiporuk A, Raible DW (2008) FGF-dependent mechanosensory organ patterning in zebrafish. Science (New York, NY) 320(5884):1774-1777. doi:10.1126/science.1156547

Rørth P (2007) Collective guidance of collective cell migration. Trends Cell Biol 17(12):575-579. doi:10. 1016/j.tcb.2007.09.007

Serra-Picamal X, Conte V, Vincent R, Anon E, Tambe DT, Bazellieres E, Trepat X (2012) Mechanical waves during tissue expansion. Nat Phys 8(8):628-634

Sherratt JA, Murray JD (1990) Models of epidermal wound healing. Proc Biol Sci/R Soc 241(1300):29-36. doi: $10.1098 /$ rspb.1990.0061

Sherratt JA, Murray JD (1991) Mathematical analysis of a basic model for epidermal wound healing. J Math Biol 29(5):389-404

Streichan SJ, Valentin G, Gilmour D, Hufnagel L (2011) Collective cell migration guided by dynamically maintained gradients. Phys Biol 8(4):045004. doi:10.1088/1478-3975/8/4/045004

Taber LA (2004) Nonlinear theory of elasticity: applications in biomechanics. World Scientific, Singapore

Tambe DT, Hardin CC, Angelini TE, Rajendran K, Park CY, Serra-Picamal X, Trepat X (2011) Collective cell guidance by cooperative intercellular forces. Nat Mater 10(6):469-475. doi:10.1038/nmat3025

Trepat X, Wasserman MR, Angelini TE, Millet E, Weitz DA, Butler JP, Fredberg JJ (2009) Physical forces during collective cell migration. Nat Phys 5(6):426-430. doi:10.1038/nphys1269

Valentin G, Haas P, Gilmour D (2007) The chemokine SDF1a coordinates tissue migration through the spatially restricted activation of Cxcr7 and Cxcr4b. Curr Biol 17(12):1026-1031. doi:10.1016/j.cub. 2007.05.020

Vedel S, Tay S, Johnston DM, Bruus H, Quake SR (2013) Migration of cells in a social context. Proc Natl Acad Sci 110(1):129-134. doi:10.1073/pnas.1204291110

Vitorino P, Meyer T (2008) Modular control of endothelial sheet migration. Genes Dev 22(23):3268-3281. doi:10.1101/gad.1725808

Yamao M, Naoki H, Ishii S (2011) Multi-cellular logistics of collective cell migration. PLoS One 6(12):e27950. doi:10.1371/journal.pone.0027950 